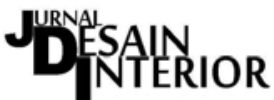

Vol. 3, No. 2, Desember 2018, pISSN 2527-2853, eISSN 2549-2985

\section{Desain, Urinoir, dan Pria \\ Studi Kasus: Toilet Umum Pria Paris Van Java (PVJ) Mall - Bandung}

\author{
Mahendra Nur Hadiansyah \\ Dosen, Program Studi Desain Interior, Universitas Telkom, Bandung, Indonesia \\ mahendrainterior@telkomuniversity.ac.id
}

\begin{abstract}
ABSTRAK
Buang air kecil adalah kegiatan manusia rutin yang dilakukan selama berkegiatan dalam kehidupan. Toilet umum adalah salah satu fasilitas publik yang dimiliki oleh sebagian besar masyarakat perkotaan yang sibuk dengan pekerjaan dan kegiatan di luar rumah. Hal ini yang menyebabkan kemungkinan "aurat" (privasi visual) dilihat oleh orang lain ketika mereka berada di toilet. Area urinoir pada pria dianggap cukup berisiko terhadap penurunan tingkat privasi pengguna dari sisi visual sehingga berdampak pada psikologi pengguna yang menggunakan urinoir secara tidak maksimal. Penelitian ini bertujuan untuk mengidentifikasi kenyamanan pengguna dan masalah keamanan yang timbul berdasarkan dampak dari desain area urinoir dan penataan interior pada toilet pria. Metode penelitian melalui observasi yang disinergikan dengan data pengguna menggunakan studi kasus, yaitu toilet pria di mal Paris Van Java (PVJ) Bandung. Secara garis besar, hal-hal yang mempengaruhi tingkat kenyamanan dan keamanan pengguna urinal dalam privasi visual muncul dari desain bentuk produk urinoir yang digunakan, penggunaan penyekat antar urinoir, jarak antar urinoir, dan arah hadap urinoir terkait sirkulasi antar pengguna toilet yang mempengaruhi jangkauan visual. Hasil penelitian ini diharapkan dapat menjadi acuan dalam meningkatkan kualitas desain interior toilet umum, terutama area urinoir yang dapat memberikan tingkat kenyamanan dan keamanan maksimal dalam hal privasi visual. Penelitian tidak terhindar dari kekurangan, harapannya selain mampu menjadi referensi untuk para desainer interior, penelitian berikutnya juga mampu menyempurnakan kekurangan yang ada terkait topik dan pembahasan serupa.
\end{abstract}

Kata kunci: desain; urinoir; pria; privasi visual

\section{ABSTRACT}

Urination is a routine human activity that is carried out during activities in life. Toilet are one of the public facilities that are shared by most urban communities who are busy with work and outside activities. This has caused the possibility of "aurat" (visual privacy) being seen by others when they are in a toilet. The urinal area in men's is considered to be quite risky due to a decrease in the level of user privacy from the visual side so that it has an impact on psychology and the user is not using the urinal maximally. This study aims to identify user comfort and security problems that arise based on the impact of a urinal area design and interior arrangement on men's toilets. Research methods through observation which is synergized with data of users using a case study, the namely male toliet at the Paris Van Java (PVJ) mall in Bandung. Broadly speaking, things that affect the level of comfort and safety of urinal users in visual privacy arises from the design of the urinal product form used, the use of barriers between urinals, the distance between urinals, and the direction facing the circulation between users in the toilet that affects visual range. The results of this study are expected to be a reference in improving the quality of interior design of public toilets, especially the urinal area which can provide a maximum level of comfort and security in visual privacy. Research does not avoid the shortcomings that exist, the hope is that in addition to being able to become an interior designer and the reference for the next research, it is also able to add and deliver deficiencies with similar topics and discussions.

Keywords: design; urinal; man; visual privacy 


\section{PENDAHULUAN}

Manusia dalam kesehariannya tak lepas dari kegiatan yang alami dan manusiawi sebagai makhluk hidup. Buang air (berak atau kencing) merupakan kegiatan rutin biologis manusia yang dilakukan dalam jangka waktu tertentu. Buang air bertujuan untuk membuang limbah berupa zat yang berhasil dipisahkan oleh organ dalam tubuh karena tidak dibutuhkan oleh tubuh. Maka buang air bagi manusia sangat penting dilakukan dan tidak bisa ditunda.

Masyarakat di perkotaan besar (masyarakat urban) semakin padat aktivitas. Kegiatan di luar rumah semakin menggeser prioritas kegiatan di dalam rumah. Hampir lebih dari setengah hari masyarakat ini menghabiskan waktunya di luar rumah. Hal ini yang mendorong kemunculan fasilitas yang dapat menampung kegiatan biologis manusia berupa buang air yaitu toilet. Budaya modern semakin memberikan ruang yang lebih efisien dan lebih menitik beratkan pada fungsi. Sehingga urinoir hadir sebagai solusi pemilahan kebutuhan pria saat berada dalam toilet demi untuk mengatasi padatnya sirkulasi pengunjung pada toilet pria. Namun seiring perkembangan zaman yang berdampak pada kebudayaan masyarakat modern akhirnya muncul beberapa masalah dari urinoir dan lingkungan sekitarnya.

Sebuah penelitian di Inggris yang diterbitkan melalui British Journal of Criminology menyatakan bahwa sebagian besar pria lebih tertekan jiwanya ketika menggunakan fasilitas toilet umum dibandingkan wanita. Dalam wawancara, Dr. Sarah Moore sebagai ketua penelitian mengatakan: "Para koresponden menyatakan mereka merasa terintimidasi dan tegang pada saat menggunakan toilet umum sehingga tidak dapat memanfaatkannya dengan baik”. Penelitian ini juga menyinggung tentang penyakit paruresis yaitu suatu keadaan cemas karena merasa diawasi. Keadaan ini yang membuat seseorang tidak nyaman ketika di toilet, khususnya para pria di Inggris yang menggunakan fasilitas urinoir (Kartika, 2012). Hal ini tidak jauh berbeda dengan kondisi toilet umum pria di Indonesia khususnya toilet umum Mal Paris Van Java di Bandung. Ditemukan permasalahan-permasalahan baru meski area urinoir telah didesain dengan tema atau konsep yang baik serta telah mengikuti beberapa aturan standar toilet Indonesia. Dalam ajaran semua agama di Indonesia mengajarkan bahwa manusia yang bermartabat harus menjaga dan menutup auratnya, sedangkan aktivitas pada saat buang air di toilet umum bagian aurat sangat rentan terlihat oleh orang lain. Hal tersebut yang menyebabkan betapa pentingnya desain dan penataan toilet umum agar mampu memberikan rasa aman dan nyaman yang menjaga privasi penggunanya (Budiono dan Anggraeni, 2017).

Area urinoir toilet pria di mal Paris Van Java memiliki konsep yang unik dan berbeda dari toilet pada umumnya, namun beberapa aspek desain tidak mengikuti standar toilet Indonesia yang dibuat dan ditetapkan oleh Kementrian Kebudayaan dan Pariwisata. Berdasarkan dari hasil pengamatan, terdapat beberapa hal yang menunjukkan bahwa desain area urinoir mengalami disfungsi. Para pengguna urinoir berusaha mengamati situasi sebelum menentukan pilihan urinoir yang akan digunakan. Hal tersebut dilakukan guna memperoleh tingkat kenyamanan dan keamanan yang sesuai kebutuhan. Akibat hal tersebut pengunjung toilet terkadang belum memaksimalkan fasilitas urinoir, pada kondisi tertentu pengunjung lebih memilih menggunakan kloset yang terdapat di dalam bilik daripada menggunakan urinoir yang kosong untuk membuang air kecil. Hal tersebut terjadi karena manusia memiliki sifat alamiah yang berusaha mengkondisikan diri berdasarkan situasi yang sedang dihadapi. Sifat tersebut merupakan cara manusia untuk bertahan dan meminimalkan kondisi terburuk disekitarnya saat berada di ruang publik dengan wilayah teritori pribadi yang cukup sempit (Fryer, Henry, dan Sparks, 1957). 
Vol. 3, No. 2, Desember 2018, pISSN 2527-2853, eISSN 2549-2985

\section{METODE PENELITIAN}

Metode yang digunakan melalui studi kasus yaitu toilet umum pria Mal Paris Van Java Bandung dengan langkah-langkah sebagai berikut:

1. Melakukan survei dan pengamatan pada studi kasus.

2. Penjabaran beberapa temuan fakta di lapangan berdasarkan hasil survei dan pengamatan serta wawancara dan penyebaran kuisoner kepada pengguna.

3. Analisa data yang diperoleh dari pengumpulan data di lapangan berupa desain dan elemen pembentuk interior area unoir dilanjutkan dengan mengidentifikasi masalah yang ada.

4. Penjabaran temuan penelitian dengan cara validasi melalui komparasi hasil analisa data dengan teori-teori terkait.

\section{HASIL PENELITIAN DAN PEMBAHASAN}

\section{A. Tinjauan Desain area urinoir toilet pria Mal Paris Van Java (PVJ)}

Desain area urinoir pada toilet pria mal PVJ semuanya memiliki konsep dan tema yang sama dalam desainnya. Berikut adalah foto area urinoir toilet pria mal Paris Van Java - Bandung:

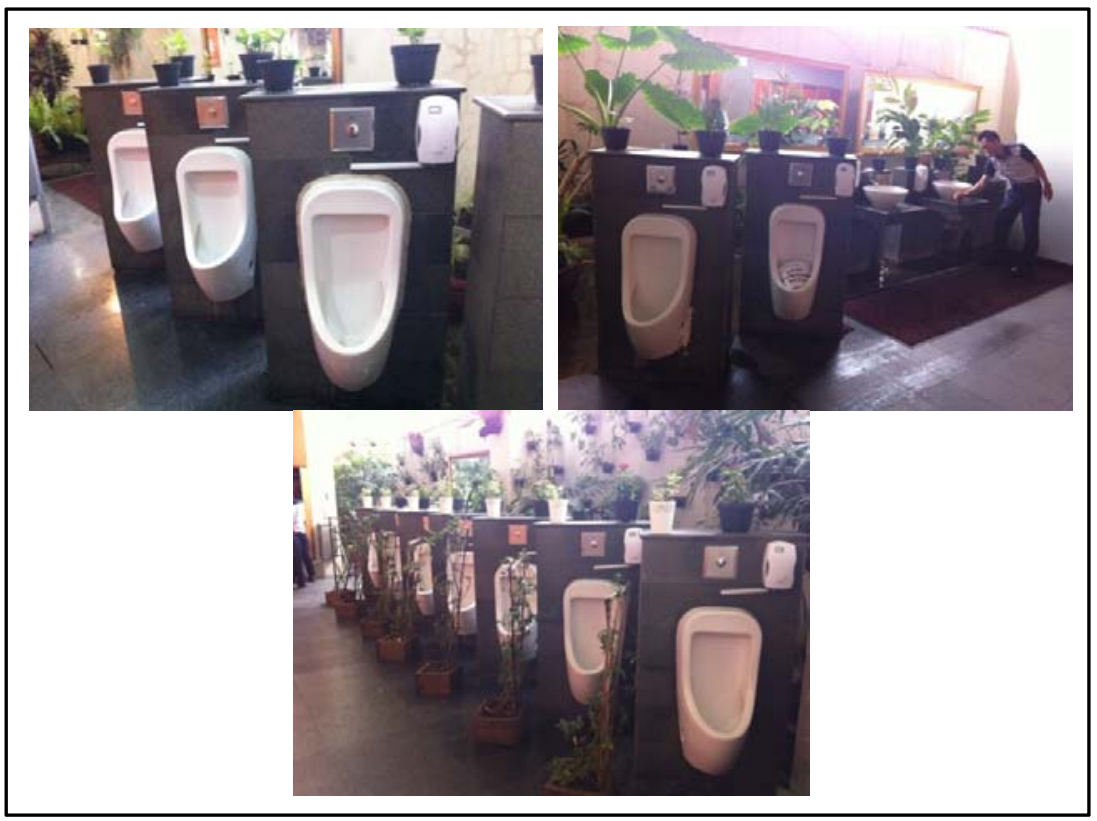

Gambar 1. Dari atas kiri: area urinoir toilet pria lantai 1, lantai 2, lantai 3 Sumber: Dokumentasi Penulis (2018)

Pemilihan bentuk urinoir menggunakan produk urinoir dengan bentuk yang mengantung. Arah hadapnya tidak sejajar (horizontal) berdampingan antara pengguna satu dengan lainnya namun setiap urinoir diarahkan berputar 30 derajat. Hal ini yang membuat desain area urinoir unik dan berbeda dengan toilet pria pada umumnya. Namun kondisi ini sangat berbeda dengan standar toilet Indonesia yang dikeluarkan oleh Kementrian Kebudayaan dan Pariwisata. Dalam pedoman teknis sebagai acuan desain dan pembangunan toilet khususnya pada area urinoir, arah hadap dalam sebuah area urinoir adalah sejajar atau antar pengguna menghadap kearah yang sama (Wibowo, et.al. (2004). Kondisi tersebut menunjukan bahwa area pengguna setiap urinoir diusahakan agar memiliki area teritori yang jauh dari jangkauan penglihatan antar sesama pengguna.

Kondisi lain menunjukkan bahwa setiap area pengguna urinoir tidak dilengkapi partisi atau penyekat yang dapat menutup bagian aurat pengguna. Berdasarkan standar toilet Indonesia 
terdapat keharusan penggunaan penyekat antar urinoir (Wibowo, et.al. 2004) selain sebagai pembatas antar aktivitas buang air kecil juga sebagai pembatas secara pandangan (visual) antar pengguna agar setiap pengguna merasakan tingkat privasi yang lebih, aman, dan nyaman. Kondisi penataan berjajar juga mempengaruhi bagaimana sudut pandang antar pengguna sehingga tidak mengganggu pandangan antar sesama pengguna yang dapat mempengaruhi tingkat privasi.

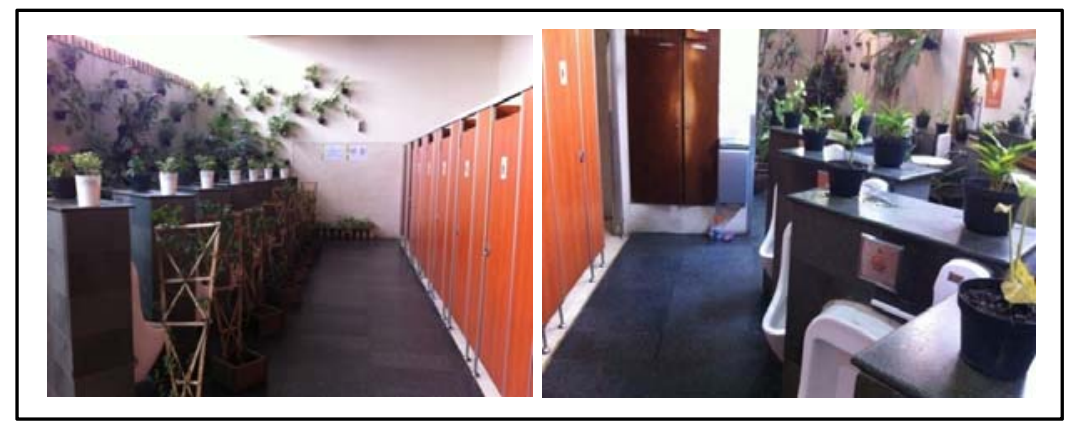

Gambar 2. Posisi area urinoir pada interior toilet Sumber: Dokumentasi Penulis (2018)

Letak atau posisi area urinoir pada interior toilet berada dibagian sisi sirkulasi pengunjung toilet yang berseberangan langsung dengan bilik-bilik kolset yang memfasilitasi buang air besar. Kondisi ini memang secara jangkauan penglihatan antar pengguna urinoir tidak bisa terjangkau, tetapi tidak dengan pengguna toilet lainnya yang ada pada jalur sirkulasi karena secara sudut pandang memberikan kemudahan jangkauan penglihatan terhadap pengguna urinoir saat buang air kecil. Jika digambarkan pada denah tampak atas, hal tersebut dapat dilihat pada ilustrasi gambar berikut:

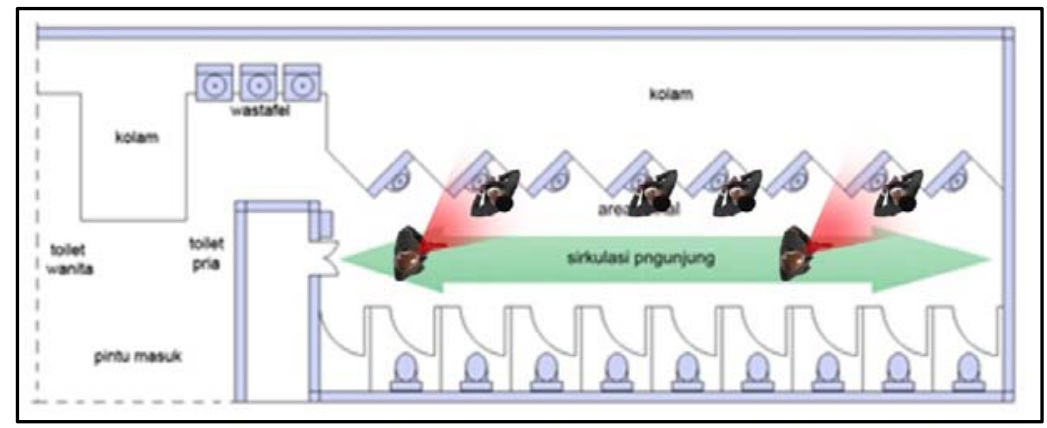

Gambar 3. Sudut pandang pengunjung dalam toilet pria PVJ Sumber: Dokumentasi Penulis (2018)

Manusia dalam ruang sosial memiliki jarak atau radius terhadap objek yang dapat dijangkau oleh panca indera. Jarak terjauh berupa jangkauan penglihatan, semakin mendekat bertambah dengan jangkauan pendengaran, lebih dekat jangkauan penciuman mampu terlibat, sedangkan jarak paling dekat semua panca indera mampu menjangkau termasuk sentuhan atau peraba (Lawson, 2001:110). Melihat jangkauan pengunjung toilet pada area sirkulasi berdasarkan alur pengunjung, hal yang sangat mungkin terjadi pada pengguna urinoir adalah rasa diawasi atau dilihat. Hal ini membuat psikologi pengguna semakin kompleks dalam menghadapi situasi dengan kondisi urinoir yang sangat terbuka dari segi bentuk dan tanpa ada elemen pendukung (partisi) semakin mengurangi tingkat privasi pengguna disetiap urinoir. 


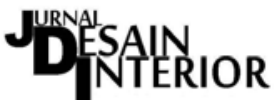

Vol. 3, No. 2, Desember 2018, pISSN 2527-2853, eISSN 2549-2985

\section{B. Faktor-Faktor yang Mempengaruhi Kenyamanan Pria pada Area Urinoir}

Toilet merupakan salah satu ruang publik yang terdapat interaksi manusia didalamnya baik terhadap sesama manusia maupun benda-benda atau objek di sekitarnya. Terdapat sebuah proses bagaimana manusia tersebut pada akhirnya membuat sebuah keputusan untuk menentukan perilaku yang akan dilakukan ketika merespon objek-objek disekelilingnya. Begitu juga yang terjadi pada pria saat berada dalam toilet ketika akan menggunakan fasilitas urinoir untuk buang air kecil. Sesuai pernyataan Fryer, Henry, dan Sparks (1957:45), terdapat faktor-faktor yang mempengaruhi kenyamanan pria saat akan dan ketika buang air kecil di area urinoir. Berdasarkan dari data yang diperoleh, dapat disimpulkan bahwa faktor-faktor tersebut berasal dari manusia sebagai subjek dan urinoir sebagai objek. Kedua hal tersebut saling bersinergi, area urinoir memiliki tanda-tanda yang dapat mempengaruhi psikologi pria untuk menentukan respon (perilaku) apa yang akan dilakukan saat akan dan ketika buang air kecil. Maka dalam hal ini untuk mengetahui faktor-faktor apa saja yang mempengaruhi kenyamanan pria pada area urinoir dapat dilakukan dengan menganalisis dari sisi psikologi pria sebagai subjek dan desain urinoir sebagai objek.

\section{Psikologi Pria}

Psikologi manusia akan bekerja ketika otak memproses (menstimulus) rangsangan yang diterima oleh alat indera saat menerima kondisi dan situasi yang ada di luar tubuh. Jika diamati mengenai kondisi pria saat akan menggunakan urinoir, alat indera yang pertama kali merespon adalah mata karena pria dalam posisi mengambil sebuah jarak dan mengatur skala untuk memetakan sebuah situasi dan kondisi dari objek. Dalam hal ini objek yang dimaksud adalah elemen-elemen desain area urinoir. Sama halnya dengan yang diutarakan Fryer, Henry, dan Sparks (1957), bahwa pengalaman visual di kehidupan sehari-hari, persepsi manusia selalu berada dalam kondisi yang kompleks saat melihat benda, peristiwa, dan hal-hal yang berkaitan. Berawal dari sebuah visual ketika otak menstimulus hasil penglihatan akan menghasilkan sebuah persepsi yang berdasarkan pengalaman yang pernah dilalui sebelumnya. Dari persepsi tersebut akhirnya muncul antisipasi (waspada) untuk menghadapi kemungkinan-kemungkinan yang akan terjadi. Persepsi tersebut menjadi modal untuk menentukan keputusan respon (perilaku) apa yang akan dilakukan. Karena pada dasarnya manusia membutuhkan ruang pribadi disetiap melakukan kegiatan pribadinya dalam kehidupan tanpa ada gangguan dari orang lain disekitarnya (Lawson, 2001:105). Maka jika diuraikan satu persatu unsur-unsur yang membentuk psikologi manusia saat mengalami proses berpikir untuk menentukan sikap dan perilaku di area urinoir dapat di skemakan sesuai alur sebagai berikut:

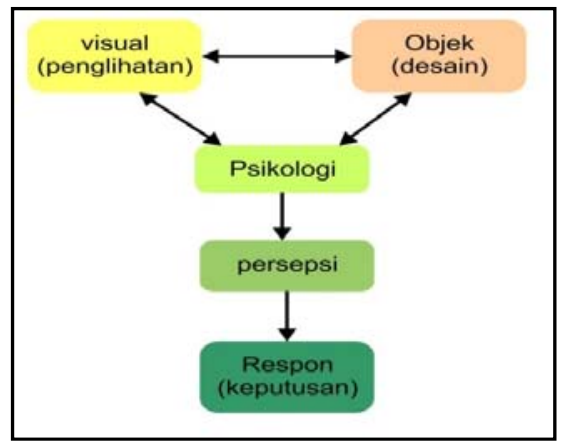

Gambar 4. Skema proses psikologi pria Sumber: Dokumentasi Penulis (2018) 
Berdasarkan dari hasil analisa yang telah dilakukan maka dapat diskemakan alur sirkulasi faktor-faktor yang mempengaruhi kenyamanan pria saat akan dan ketika menggunakan urinoir sehingga berdampak pada perilakunya (respon).

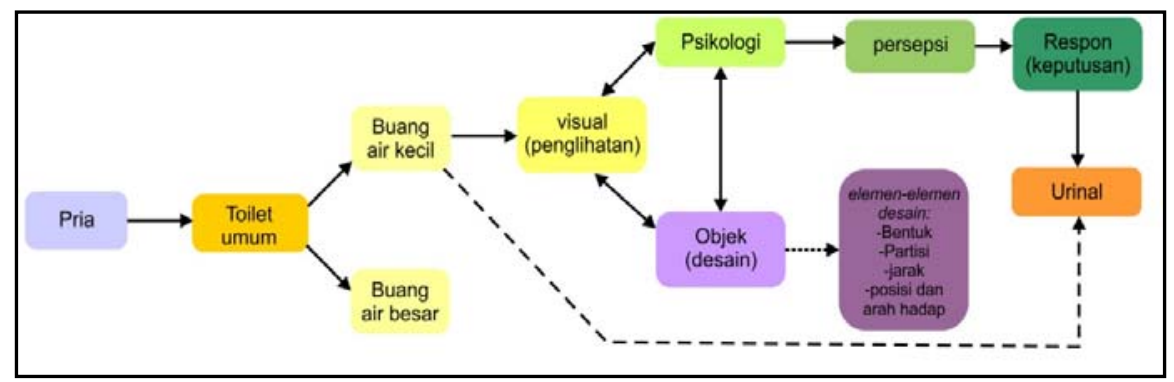

Gambar 5. Skema alur Psikologi pria dalam toilet Sumber: Dokumentasi Penulis (2018)

\section{Elemen Desain}

\section{a. Bentuk Urinoir}

Bentuk urinoir adalah salah satu yang mempengaruhi pria saat akan dan ketika buang air kecil. Menurut Fryer, Henry, dan Sparks (1957:81) faktor yang mempengaruhi psikologi adalah fisik (physical) dari sebuah bentuk dan ruang sehingga memunculkan sebuah interpretasi. Produk urinoir yang dipilih dalam desain area urinoir PVJ adalah produk yang berbentuk mengantong yang dapat dilihat pada foto berikut:

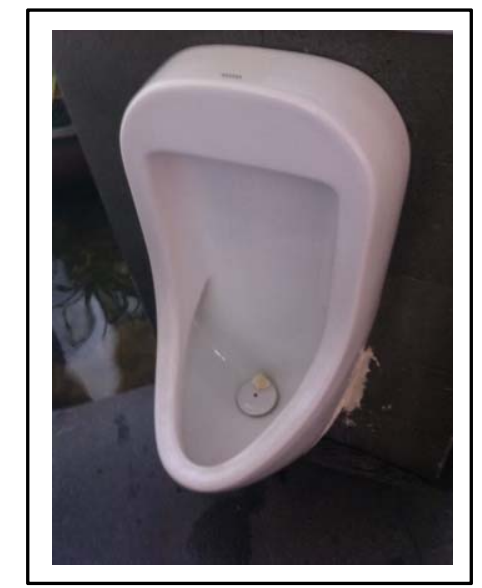

Gambar 6. Bentuk urinoir toilet PVJ Sumber: Dokumentasi Penulis (2018)

Jika diamati bentuk kantong yang terdapat dibagian bawah memiliki dimensi yang cukup besar sehingga membutuhkan jarak yang cukup jauh untuk berdiri saat melakukan buang air kecil. Sedangkan pada bagian sisi pembatas dinding dimensinya lebih kecil dibandingkan bagian bawah yang mengantong. Sehingga kesan yang dimunculkan pada bentuk urinoir ini sangat terbuka dan kurang mengakomodasi kebutuhan privasi pengguna. Hal itu karena sisi pembatas samping tersebut tidak memberikan cukup ruang yang dapat menutupi kemaluan (aurat) pria saat melakukan buang air kecil. Sedangkan pria sebagai manusia juga sangat membutuhkan ruang privasi apalagi ketika berada di lingkungan publik yang penuh dengan aktivitas orang yang tidak dikenal. Hal ini sejalan dengan Budiono dan Anggraeni (2017) bahwa setiap pria yang melakukan 
kegiatan buang air kecil teridentifikasi muncul rasa kekhawatiran terlihatnya aurat (privasi visual) oleh orang lain yang muncul dari persepsi pengguna terhadap desain urinoir.

Pemilihan bentuk urinoir sepatutnya memilih produk yang dapat memaksimalkan kebutuhan privasi pria karena urinoir merupakan faktor utama yang memfasilitasi pria saat buang air kecil, misalnya bentuk urinoir yang cekung kedalam dengan batas samping lebih lebar sehingga pengguna merasa aman dan merasa terlindungi dari jangkauan penglihatan pengunjung lainnya.

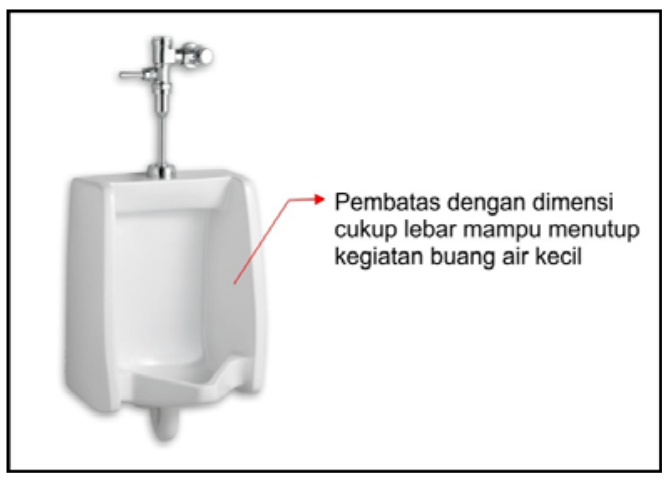

Gambar 7. Bentuk urinoir yang dianggap ideal Sumber: Dokumentasi Penulis (2018)

\section{b. Elemen Pembatas (Partisi)}

Partisi dalam desain urinoir berfungsi sebagai usaha melindungi pengguna dari jangkauan penglihatan orang lain. Namun yang terjadi pada kenyataannya bukan hanya sekedar kemunculan persepsi tentang keamanan dari jangkauan penglihatan yang dibutuhkan, tetapi adanya kontak mata dengan orang lain menimbulkan penurunan persepsi rasa aman karena merasa diawasi. Maka seharusnya sebuah partisi urinoir bukan sekedar menutupi dareah urinoir namun juga menutupi area jangkauan kontak mata dengan sesama pengguna maupun pengunjung lainnya. Sedangkan yang terjadi pada urinoir toilet PVJ, tidak dilengkapi dengan partisi yang memadai sehingga aktivitas pengguna sangat terbuka dan mudah dijangkau oleh penglihatan pengunjung lainnya. Hal ini yang menyebabkan tingkat privasi pada area urinoir toilet pria PVJ semakin rendah.

Bentuk dan dimensi pada partisi bukan sekedar berfungsi sebagai penutup kegiatan buang air kecil pada area kemaluan pria (aurat) tetapi juga didesain agar dapat menutup jangkauan visual yang memungkinkan terjadi kontak mata antara pengguna atau pengunjung (Budiono dan Anggraeni, 2017). Maka partisi yang baik adalah partisi dengan dimensi yang mampu menutup seluruh bagian kegiatan pria saat buang air kecil hingga bagian jangkauan penglihatan. Seperti penjelasan pada gambar berikut:

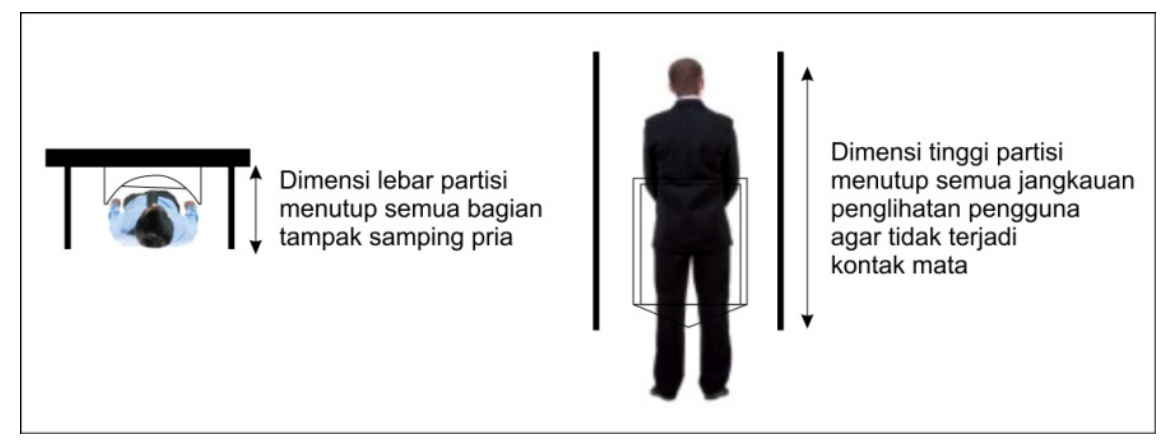

Gambar 8. Ukuran partisi yang ideal Sumber: Dokumentasi Penulis (2018) 


\section{c. Jarak Antar Urinoir}

Masalah jarak pada toilet pria PVJ berusaha diatasi melalui desain yang membuat pengguna tidak dekat dengan pengguna lainya dengan cara memutar arah hadap menjadi miring kurang lebih 30 derajat. Kondisi arah hadap yang sama membuat pengguna tidak berdampingan dengan pengguna lainnya namun kewaspadaan tetap muncul karena merasa diawasi oleh pengguna dibelakangnya. Hal tersebut terjadi karena dinding penopang urinoir dibangun setinggi batas kebutuhan sanitasi urinoir saja, sehingga secara visual pengguna masih bisa melihat dengan leluasa pengguna di depannya.

Jarak sesama manusia merupakan faktor yang dapat memunculkan persepsi yang diperoleh dari sesama subjek. Subjek lainnya akan berubah menjadi objek ketika berada dalam psikologi pria. Lawson (2001:115) menjelaskan tentang sifat ruang berdasarkan jarak antar manusia. Jarak hingga 0,5 meter bersifat intim, jarak antara 0,5 meter sampai 1,2 meter bersifat personal, sedangkan jarak antara 1,2 meter sampai 4 meter bersifat sosial, dan jarak diatas 4 meter bersifat publik.

Untuk menghindari sifat intim, maka jarak antar pengguna harus lebih dari 0,5 meter yang merupakan batas jarak terjauh dari sifat intim. Maka setidaknya jarak minimal yang dipakai adalah jarak yang mendekati yaitu 0,6 meter $(60 \mathrm{~cm})$. Jarak diambil dari bahu ke bahu lebar pria yaitu 50 cm, karena lebar ukuran pria standar kurang lebih 50-55 cm (Panero \& Zelnik, 2003), maka seharusnya jarak penempatan urinoir yang ideal adalah (minimal) 110 sentimeter, diukur antara as ke as. Seperti pada penjelasan gambar berikut:

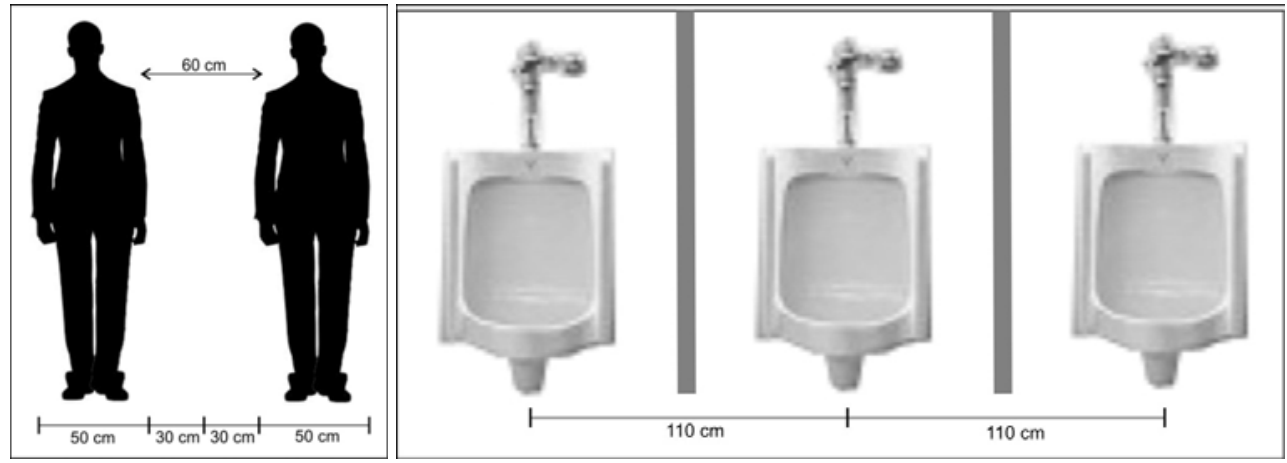

Gambar 9. Jarak ideal minimal aagar bersifat tidak intim (personal) Sumber: Dokumentasi Penulis (2018)

\section{d. Letak dan Arah hadap Urinoir}

Letak dan arah hadap antar urinoir pada toilet umum pria PVJ memang sengaja ditata secara tidak sejajar, tingkat privasi antar pengguna memang semakin tinggi karena tidak bersebelahan. Namun kendala baru terjadi karena tingkat privasi menurun karena justru bersebelahan dengan area atau jalur sirkulasi utama masuk dan keluarnya pengunjung toilet. Selain itu tingkat privasi semakin menurun karena tidak terdapat penyekat yang tertutup maksimal atau bahkan tidak ada sama sekali sehingga secara sudut pandang dapat terlihat oleh pengunjung yang datang. Maka sebaiknya desain area urinoir mampu memperkecil kemungkinan kontak mata antar pengguna dan pengunjung dengan cara memposisikan pengguna urinoir jauh dari jangkauan penglihatan. Dalam perwujudannya arah hadap sejajar dengan arah hadap yang sama dan berdampingan dengan jangkauan mata bertolak dengan pengguna dan pengunjung lainnya, seperti pada gambar berikut: 
Vol. 3, No. 2, Desember 2018, pISSN 2527-2853, eISSN 2549-2985

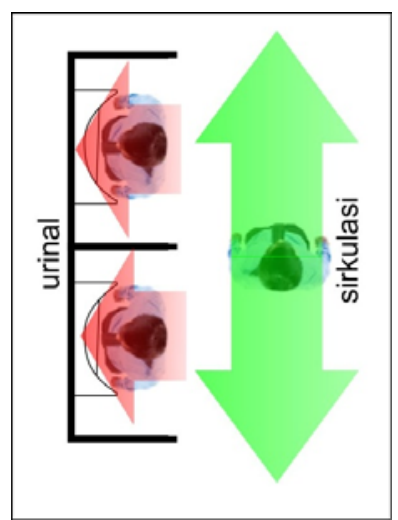

Gambar 10. Arah hadap terhadap posisi sirkulasi yang ideal Sumber: Dokumentasi Penulis (2018)

\section{KESIMPULAN}

Desain area urinoir sepatutnya bukan sekedar bersih, ergonomis, estetis, dan fungsional. Tetapi juga mampu mengakomodasi kebutuhan pengguna (pria) dari aspek psikologi, yaitu dapat memberikan rasa aman dalam melindungi auratnya saat beraktivitas buang air kecil. Sehingga mampu meminimalisir jangkauan visual pengguna toilet lainnya dengan ketentuan sebagai berikut: 1. Urinoir memiliki jarak yang ideal, sehingga mampu memberikan rasa aman dan nyaman baik antar sesama pengguna, maupun pengguna dengan pengunjung toilet lainnya dalam hal jangkauan penglihatan yang berpengaruh terhadap privasi visual.

2. Pemilihan produk urinoir yang tepat, sehingga mampu mereduksi kemungkinan-kemungkinan yang dapat mengurangi tingkat privasi pengguna.

3. Posisi urinoir berdasarkan arah hadap dan penempatan area urinoir harus mampu bersinergi dengan psikologi pengguna dalam interior toilet umum yang dapat mempertahankan keprivasian pengguna terhadap jangkauan penglihatan pengguna toilet lainnya.

4. Penggunaan elemen pendukung partisi (pembatas) dengan desain dan dimensi yang tepat guna dapat menambah tingkat privasi antar urinoir yang disesuaikan dengan kebutuhan hingga mendekati titik maksimal baik secara kenyamanan maupun kenamanan secara fisik dan visual antar pengguna toilet.

\section{DAFTAR PUSTAKA}

Budiono, B., \& Anggraeni, L. K. (2017). Desain Toilet dan Tempat Wudhu Masjid. Jurnal Desain Interior, 2(1), 1-12

Fryer, H. Douglas, Henry, R. Edwin, and Sparks, P. Charles. (1957). General Psychology. New York: Barners \& Noble, Inc.

Kartika, Unoviana. (2012). Masuk Toilet, Pria lebih Stress?, diambil dari http://health.kompas.com/read/2012/11/28/07453488/Masuk.Toilet.Umum.Pria.Lebih.Stre S.

Wibowo, et.al (2004). Standard Toilet Umum Indonesia "Kering itu Sehat". Kementerian Kebudayaan dan Pariwisata.

Lawson, Bryan. (2001). The Language of Space. London: Architectural Press, Oxford.

Panero, Julius/Martin Zelnik. (2003). Dimensi Manusia \& Ruang Interior. Jakarta: Erlangga. 
Mahendra Nur Hadiansyah

Desain, Urinoir, dan Pria, Studi Kasus: Toilet Umum Pria Paris Van Java (PVJ) Mall - Bandung 